\title{
GENETIC POLYMORPHISMS OF COMPLEMENT COMPONENTS C6 AND C7 IN KOREAN
}

\author{
Kyung Sook Park, ${ }^{1}$ Masami Yanagisawa, ${ }^{2}$ Katsushi TokunaGa, ${ }^{2}$ \\ and Keiichi Омото ${ }^{2}$ \\ ${ }^{1}$ Department of Biology, Sung-Shin Women's University, \\ Seoul 136, Korea \\ ${ }^{2}$ Department of Anthropology, The University of Tokyo, \\ Tokyo 113, Japan
}

\begin{abstract}
Summary Genetic polymorphisms of the complement components C6 and $\mathrm{C} 7$ were investigated in Korean living in Seoul using isoelectric focusing and immunoblotting. Three common and four rare $\mathrm{C} 6$ allotypes were observed. The allele frequencies estimated were as follows: $C 6^{*} A 0.433$, $C 6^{*} B$ 0.523, $C 6^{*} B 2$ 0.039, and rare alleles (M91, M92, M11 and M2) 0.005 . Three $\mathrm{C} 7$ variants, besides a common allele, were observed with polymorphic frequencies. Two rare $\mathrm{C} 7$ variants, considered to be new, were also observed. The allele frequencies estimated for $C 7^{*} 1, C 7^{*} 2, C 7^{*} 3, C 7^{*} 4$, and rare variants (tentatively named $\mathrm{K} 1$ and $\mathrm{K} 2$ ) were $0.843,0.073,0.034$, 0.048 and 0.002 , respectively. The $\mathrm{C} 6$ and $\mathrm{C} 7$ allele frequencies are similar to those in Japanese and Chinese. The association analysis between $\mathrm{C} 6$ and C7 showed a significant negative association between C6 B and C7 4 allotypes $(\mathrm{p}<0.02)$.
\end{abstract}

\section{INTRODUCTION}

Genetically determined polymorphisms have been shown for most human complement proteins. Polymorphism of the sixth component (C6) was first described by Hobart et al. (1975). Two predominant alleles, C6*A and $\mathrm{C} 6{ }^{*} \mathrm{~B}$, and several rare alleles have been described in Caucasian populations (Hobart and Lachmann, 1976; Kühnl and Kreckel, 1980; Kunstmann et al., 1980). The variants are designated according to their relative isoelectric points (Mauff et al., 1980). The introduction of an immunoblotting method after isoelectric focusing in polyacrylamide gel enabled us to carry out extensive population surveys (Tokunaga et al., 1984). It is interesting that $C 6^{*} B$ is commoner than $C 6^{*} A$ and that the third 
common allele, $C 6^{*} B 2$, and a number of rare variants have been found in Japanese and in Mainland Chinese populations (Tokunaga et al, 1983, 1984; Washio et al., 1986; Zeng et al., 1986).

Genetic variation of the seventh component of complement (C7) was first detected by Hobart et al. (1978). They reported a common allele, $C 7 * 1$, and two rare variants, $C 7 * 2$ and $C 7 * 3$, in a Caucasian population. Close linkage between C6 and C7 loci has been established (Hobart et al., 1978; Tokunaga et al., 1986). Isoelectric focusing with neuraminidase-treated plasma and subsequent immunoblotting have been established as a suitable method for C7 typing (Nakamura et al., 1984a; Nishimukai and Tamaki, 1986; Washio et al., 1986). Interestingly, besides the commonest allele, $C 7^{*} 1$, at least three variants, $C 7^{*} 2, C 7^{*} 3$ and $C 7^{*} 4$, occur with polymorphic frequencies in Japanese and in Mainland Chinese populations (Washio et al., 1986; Zeng et al., 1986).

Previously, we have reported the genetic polymorphisms of the second complement component (C2) and factor B (BF) in Korean (Park et al., 1985). The purpose of this study was to investigate the allelic distribution of the linkage group C6 and $\mathrm{C} 7$ in Korean. The result of an association analysis between $\mathrm{C} 6$ and C7 alleles is also presented.

\section{MATERIALS AND METHODS}

EDTA-plasma samples were obtained from 490 healthy blood donors living in Seoul, Korea. Typing of C6 and C7 was carried out using polyacrylamide gel isoelectric focusing and immunoblotting as described previously (Tokunaga et al., 1984; Washio et al., 1986). Briefly, isoelectric focusing (pH 5-8) was performed in a thin layer $(0.5 \mathrm{~mm}$ thick) polyacrylamide gel. Native plasma or neuraminidase-treated plasma was applied for C6 or C7 typing, respectively. After focusing, proteins were transferred on to a polyvinyden fluoride filter (Durapore, Millipore) by press blotting, and then $\mathrm{C} 6$ or $\mathrm{C} 7$ bands were detected by a two step enzyme immunoassay.

\section{RESULTS}

\section{C6 polymorphism}

The C6 patterns observed in the present study are demonstrated in Fig. 1. Five common and four rare phenotypes were observed, in which seven allotypes were distinguishable. Three common allotypes, A, B and B2, and four rare allotypes, M2, M11, M91 and M92, were identified by direct comparison with our reference samples (Tokunaga et al., 1983, 1984; Washio et al., 1986). The distribution of C6 phenotypes and allele frequencies are shown in Table 1 . The allele frequencies estimated for $C 6^{*} A, C 6^{*} B, C 6^{*} B 2$, and the rare variants combined are $0.433,0.523$, 0.039 and 0.005 , respectively. The observed numbers of the phenotypes were in good agreement with those expected on Hardy-Weinberg equilibrium. 


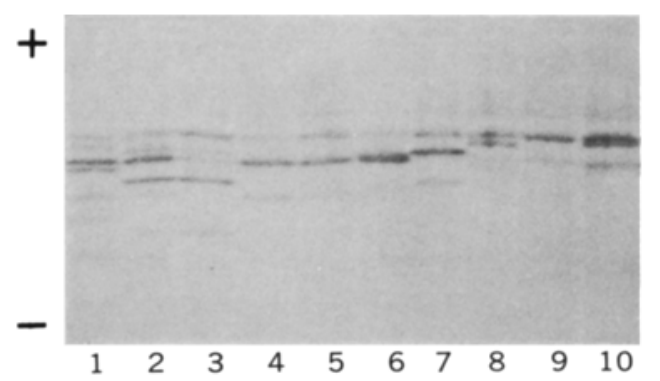

Fig. 1. Photograph showing C6 phenotypes. (1) BB1 control, (2) BB2, (3) AB2, (4) B, (5) AB, (6) M2B, (7) AM11, (8) AM91, (9) A, (10) AM92.

Table 1. Distribution of $\mathrm{C} 6$ phenotypes and allele frequencies.

\begin{tabular}{lrrrr}
\hline Phenotypes & $\begin{array}{c}\text { No. } \\
\text { observed }\end{array}$ & $\%$ & $\begin{array}{c}\text { No. } \\
\text { expected }\end{array}$ & Allele frequencies \\
\hline A & 93 & 19.0 & 91.7 & \\
AB & 220 & 44.9 & 222.0 & $C 6^{*} A=0.433$ \\
B & 134 & 27.3 & 134.3 & $C 6^{*} B=0.523$ \\
AB2 & 15 & 3.1 & 16.4 & \\
BB2 & 23 & 4.7 & 19.9 & $C 6^{*} B 2=0.039$ \\
B2 & 0 & 0.0 & 0.7 & $C 6^{*} R=0.005$ \\
AR & 3 & 0.6 & 2.2 & \\
BR $^{2}$ & 2 & 0.4 & 2.6 & 1.000 \\
Others & 0 & 0.0 & 0.2 & \\
\hline Total & 490 & 100.0 & 490.0 & \\
\hline
\end{tabular}

${ }^{\text {a }}$ Rare phenotypes: AM91 1, AM92 1, AM11 1, M2B 2. $\chi^{2}=2.06$, d.f. $=5,0.80<\mathrm{p}<0.90$.

\section{C7 polymorphism}

The patterns of neuraminidase-treated $\mathrm{C} 7$ observed in the present study are demonstrated in Fig. 2. Four common and six rare phenotypes were observed, in which six allotypes were distinguishable. Four common allotypes have been identified as C7 1, 2, 3 and 4, respectively (Hobart et al., 1978; Tokunaga et al., 1986; Washio et al., 1986). Two rare variants seem to be the new variants (Fig. 2b). One of them, tentatively named as $\mathrm{K} 1$, has a mobility slightly anodal to $\mathrm{C} 71$. The other, tentatively named as $\mathrm{K} 2$, has a mobility slightly cathodal to $\mathrm{C} 74$.

The distribution of $\mathrm{C} 7$ phenotypes and allele frequencies are shown in Table 2. The allele frequencies estimated for $C 7^{*} 1, C 7^{*} 2, C 7 * 3, C 7 * 4$ and the rare variants combined are $0.843,0.073,0.034,0.048$ and 0.002 , respectively. The observed numbers of the phenotypes were in agreement with Hardy-Weinberg expectation. 

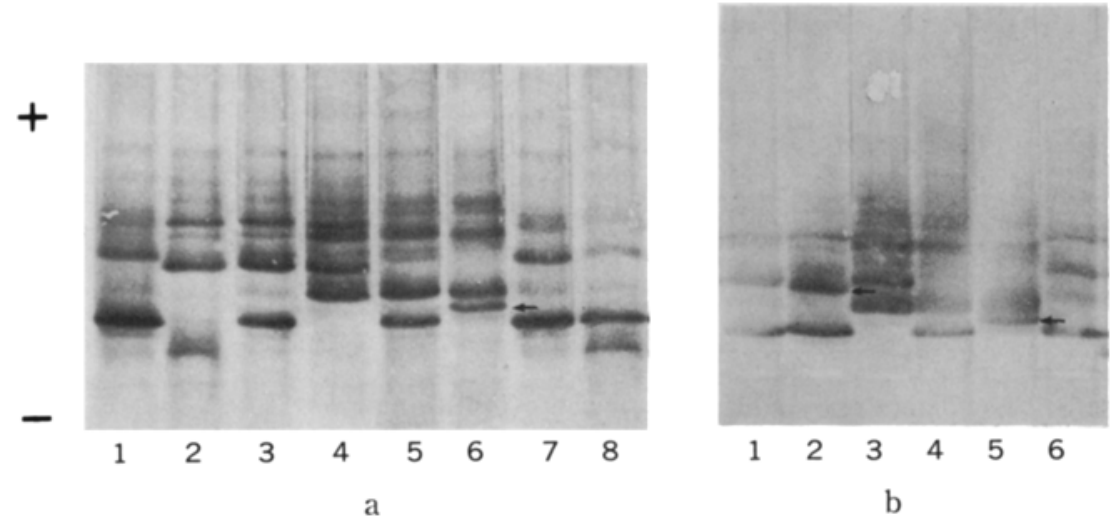

Fig. 2. Photographs showing C7 phenotypes. The arrow indicates the variant band, K1 and K2. a: (1) 1 , (2) 4-3, (3) 4-1, (4) 4-2, (5) $2-1$, (6) $2-\mathrm{K} 1$, (7) 1 , (8) 3-1. b: (1) 4-1, (2) 1-K2, (3) 4-2, (4) 2-1, (5) 2-K1, (6) 1.

Table 2. Distribution of $\mathrm{C} 7$ phenotypes and allele frequencies.

\begin{tabular}{ccccc}
\hline Phenotypes & $\begin{array}{c}\text { No. } \\
\text { observed }\end{array}$ & $\%$ & $\begin{array}{c}\text { No. } \\
\text { expected }\end{array}$ & Allele frequencies \\
\hline 1 & 347 & 70.8 & 348.1 & \\
$2-1$ & 62 & 12.7 & 60.7 & $C 7^{*} I=0.843$ \\
$3-1$ & 31 & 6.3 & 27.8 & \\
$4-1$ & 38 & 7.8 & 39.6 & $C 7^{*} 2=0.073$ \\
$3-2$ & 0 & 0.0 & 2.4 & $C 7^{*} 3=0.034$ \\
$4-2$ & 3 & 0.6 & 3.5 & $C 7^{*} 4=0.048$ \\
$4-3$ & 2 & 0.4 & 1.6 & $C 7^{*} R=0.002$ \\
2 & 3 & 0.6 & 2.6 & \\
3 & 0 & 0.0 & 0.6 & 1.000 \\
\hline
\end{tabular}

a Rare phenotypes: 2-K1 1, 1-K2 1. $\chi^{2}=4.33$, d.f. $=6,0.60<\mathrm{p}<0.70$.

Association analysis between $\mathrm{C} 6$ and $C 7$

The results of the association analysis between $\mathrm{C} 6$ and $\mathrm{C} 7$ are summarized in Table 3. A significantly negative association was observed between C6 B and C7 4 allotypes $\left(\chi^{2}=6.47, \mathrm{p}<0.02\right)$. 
Table 3. Association analysis between $\mathrm{C} 6$ and $\mathrm{C}$.

\begin{tabular}{crrrrl}
\hline Combinations $^{\text {a }}$ & $+/+$ & $+/-$ & $-/+$ & $-/-$ & $\mathrm{p}$ \\
\hline C6A-C7 1 & 325 & 6 & 154 & 5 & NS b \\
C6A-C7 2 & 50 & 281 & 19 & 140 & NS \\
C6A-C7 3 & 20 & 311 & 13 & 146 & NS \\
C6A-C7 4 & 33 & 298 & 12 & 147 & NS \\
C6B-C7 1 & 373 & 6 & 106 & 5 & NS \\
C6B-C7 2 & 54 & 325 & 15 & 96 & NS \\
C6B-C7 3 & 28 & 351 & 5 & 106 & NS \\
C6B-C7 4 & 28 & 351 & 17 & 94 & $<0.02$ \\
C6B2-C7 1 & 38 & 0 & 442 & 10 & NS \\
\hline
\end{tabular}

a Only the combinations in which the incidence of the $+1+$ individuals exceeding 0.01 are presented. b NS, not significant.

\section{DISCUSSION}

The C6 allele frequencies reported in the East Asian populations are listed in Table 4 (Nishimukai et al., 1985; Tokunaga et al., 1983, 1984; Zeng et al., 1986) together with those in the Caucasian population (Kunstmann et al., 1980). The allele frequencies obtained in the present study are similar to those in the neighboring populations. It is confirmed that the East Asian population has characteristics of

Table 4. $\mathrm{C} 6$ allele frequencies in East Asian and Caucasian populations.

\begin{tabular}{|c|c|c|c|c|c|c|}
\hline \multirow{2}{*}{ Populations } & \multirow{2}{*}{$\begin{array}{c}\text { No. } \\
\text { samples }\end{array}$} & \multicolumn{4}{|c|}{ C6 alleles } & \multirow{2}{*}{ Authors } \\
\hline & & A & $\mathrm{B}$ & $\mathbf{B} 2$ & Others & \\
\hline \multicolumn{7}{|l|}{ Korean } \\
\hline Seoul & 490 & 0.433 & 0.523 & 0.039 & 0.005 & Present study \\
\hline \multicolumn{7}{|l|}{ Japanese } \\
\hline Northeastern & 495 & 0.423 & 0.510 & 0.062 & 0.005 & Tokunaga et al., 1984 \\
\hline Tokyo & 288 & 0.427 & 0.483 & 0.076 & 0.014 & Tokunaga et al., 1983 \\
\hline Western & 135 & 0.467 & 0.481 & 0.037 & 0.015 & Nishimukai et al., 1985 \\
\hline \multicolumn{7}{|l|}{ Chinese } \\
\hline Beijing & 155 & 0.416 & 0.532 & 0.042 & 0.010 & Zeng et al., 1986 \\
\hline Guangzhou & 255 & 0.445 & 0.518 & 0.033 & 0.004 & Zeng et al., 1986 \\
\hline \multicolumn{7}{|l|}{ German } \\
\hline Köln & 709 & 0.601 & 0.388 & 0.003 & 0.008 & Kunstmann et al., 1980 \\
\hline
\end{tabular}

Vol. 33, No. 3, 1988 
Table 5. C7 allele frequencies in East Asian and Caucasian populations.

\begin{tabular}{|c|c|c|c|c|c|c|c|}
\hline \multirow{2}{*}{ Populations } & \multirow{2}{*}{$\begin{array}{c}\text { No. } \\
\text { samples }\end{array}$} & \multicolumn{5}{|c|}{ C7 alleles } & \multirow{2}{*}{ Authors } \\
\hline & & 1 & 2 & $3(=5)$ & 4 & Others & \\
\hline \multicolumn{8}{|l|}{ Korean } \\
\hline Seoul & 490 & 0.843 & 0.073 & 0.034 & 0.048 & 0.002 & Present study \\
\hline \multicolumn{8}{|l|}{ Japanese } \\
\hline Eastern & 217 & 0.813 & 0.097 & 0.037 & 0.051 & 0.002 & Washio et al., 1986 \\
\hline Western & 183 & 0.809 & 0.104 & 0.049 & 0.038 & - & $\begin{array}{c}\text { Nishimukai and } \\
\text { Tamaki, } 1986\end{array}$ \\
\hline \multicolumn{8}{|l|}{ Chinese } \\
\hline Beijing & 152 & 0.865 & 0.069 & 0.020 & 0.043 & 0.003 & Zeng et al., 1986 \\
\hline Guangzhou & 255 & 0.884 & 0.075 & 0.031 & 0.010 & - & Zeng et al., 1986 \\
\hline Caucasian (UK) & 1,228 & 0.995 & 0.002 & 0.004 & - & - & Hobart et al., 1978 \\
\hline
\end{tabular}

a higher frequency of $C 6^{*} B$ than $C 6^{*} A$, the occurrence of the third common allele, $C 6^{*} B 2$, and the existence of a number of rare alleles.

Table 5 shows the $\mathrm{C} 7$ allele frequencies reported in the East Asian populations (Nishimukai and Tamaki, 1986; Washio et al., 1986; Zeng et al., 1986) as well as in the Caucasian population (Hobart et al., 1978). The present data on Korea are similar to those in the neighboring populations. The East Asian population may be characterized by the relatively high frequencies of $C 7^{*} 2, C 7 * 3$ and $C 7 * 4$.

Accordingly, both of the proteins coded by the closely linked complement genes, C6 and C7, show a higher degree of polymorphism in East Asian than in Caucasian populations. Thus, C6 and C7 systems are particularly valuable markers for the study of human populations in Asia.

A significantly nagative association between $\mathrm{C} 6$ and $\mathrm{C} 7$ allotypes was observed in the present study. However, all the previous studies on an extensive family material (Tokunaga et al., 1986) and on several population materials (Nishimukai and Tamaki, 1986; Washio et al., 1986; Zeng et al., 1986) have failed to show any linkage disequilibrium or association, except for the report by Nakamura et al. (1984b), in which a significantly positive association between C6 B and C7 B $(=\mathrm{C} 71)$ was described. Further studies are required to confirm the possible association between $\mathrm{C} 6$ and $\mathrm{C} 7$ alleles.

\section{REFERENCES}

Hobart, M.J., Lachmann, P.J., and Alper, C.A., 1975. Polymorphism of human C6. In Protides of the Biological Fluids, 22nd Colloquim Brugge 1974, Peeters, H., ed., Pergamon Press, Oxford, pp. 575-580.

Hobart, M.J. and Lachmann, P.J. 1976. Allotypes of complement components in man. Transplant. Rev. 32: 26-42. 
Hobart, M.J., Joysey, V., and Lachmann, P.J. 1978. Inherited structural variation and linkage relationships of C7. J. Immunogenet. 5: 157-163.

Kühnl, P. and Kreckel, P. 1980. C6 phenotypes and allele frequencies in a German population. Immunobiology 158: 50-54.

Kunstmann, G., Mauff, G., and Pulverer, G. 1980. C6 polymorphism and rare alleles in Western Germany. Immunobiology 158: 55-59.

Mauff, G., Alper, C.A., Hobart, M.J., Kühnl, P., Kunstmann, G., Meo, T., Olving, J.H., and Rittner, C. 1980. Statement on the nomenclature of human C6 polymorphism. Immunobiology 158: 139-143.

Nakamura, S., Ooue, O., and Abe, K. 1984a. Genetic polymorphism of the seventh component of complement in a Japanese population. Hum. Genet. 66: 279-281.

Nakamura, S., Ooue, O., Akiyama, K., and Abe, K. 1984b. Genetic polymorphism of complement $\mathrm{C} 6$ and haplotype analysis between $\mathrm{C} 6$ and $\mathrm{C} 7$ in a Japanese population. Hum. Genet. 68: $138-141$.

Nishimukai, H., Kitamura, H., and Tamaki, Y. 1985. C6 polymorphism in Japanese: typing by agarose gel isoelectric focusing-immunofixation. Hum. Hered. 35: 30-33.

Nishimukai, H. and Tamaki, Y. 1986. Genetic polymorphisms of the seventh component of complement: a new variant. Vox Sang. 51: 60-62.

Park, K.S., Tokunaga, K., and Omoto, K. 1985. Genetic polymorphism of human complement components $\mathrm{BF}$ and $\mathrm{C} 2$ in Korean: Population and association studies. Jpn. J. Human Genet. 30: $9-14$.

Tokunaga, K., Yukiyama, Y., and Omoto, K. 1983. Polymorphism of the complement component C6 in Japanese. J. Immunogenet. 10: 419-424.

Tokunaga, K., Yamamura, N., and Omoto, K. 1984. An immunoblotting technique for complement $C 6$ typing: three new variants. Jpn. J. Human Genet. 29: 415-419.

Tokunaga, K., Dewald, G., Omoto, K., and Juji, T. 1986. Family study on the polymorphisms of the sixth and seventh components (C6 and C7) of human complement: Linkage and haplotype analyses. Am. J. Hum. Genet. 39: 414-419.

Washio, K., Tokunaga, K., Omoto, K., and Misawa, S. 1986. Human C7 polymorphism: classification and association analysis with C6. Jpn. J. Human Genet. 31: 345-352.

Zeng, Z., Tokunaga, K., Omoto, K., and Du, C. 1986. Genetic polymorphisms of complement C6 and $\mathrm{C} 7$ in two Chinese populations. Jpn. J. Human Genet. 31: 263-271. 